\title{
Tangeritin attenuates oxidative stress, apoptosis and inflammation in cadmium-induced cardiotoxicity in rats by activating Nrf2 signaling pathway
}

\author{
Dapeng Zhang ${ }^{1 *}$, Li Hou², Wenhua Peng ${ }^{3}$ \\ ${ }^{1}$ Heart Center \& Beijing Key Laboratory of Hypertension Disease, Beijing Chaoyang Hospital, Capital Medical University, \\ ${ }^{2}$ National Research Institute for Health and Family Planning, ${ }^{3}$ Department of Cardiology, China-Japan Friendship Hospital, \\ Chaoyang, Beijing 100029, China
}

*For correspondence: Email: DWilandachen@yahoo.com; Tel: 0086-010-8888888

\begin{abstract}
Purpose: To determine the effect of tangeritin on cadmium-induced cardiotoxicity in rats. Methods: Cardiotoxicity was induced by intra-gastric administration of $5 \mathrm{mg} / \mathrm{kg}$ cadmium chloride to rats, once daily for 4 weeks. The animals were treated with tangeritin at 10 and $20 \mathrm{mg} / \mathrm{kg} \mathrm{p.0.} 60 \mathrm{~min}$ before the administration of cadmium, for 4 weeks. Thereafter, the concentrations of cadmium in serum and cardiac tissue were determined, and markers of cardiac function, antioxidant enzyme activities and levels of pro-inflammatory mediators were evaluated in cardiac tissues. Histopathological examination and western blot assay were also performed.

Results: Treatment with tangeritin significantly decreased the cadmium levels in the heart tissue and serum of the cadmium-exposed rats, when compared to the negative control group $(p<0.01)$. There was significant decrease in cardiac function markers in the tangeritin-treated rats, relative to negative control group $(p<0.01)$. However, antioxidant enzyme activity and levels of pro-inflammatory mediators were attenuated in the cardiac tissues of cadmium-treated rats by tangeritin treatment. Expressions of $\mathrm{HO}-1$ and Nrf-2 were significantly enhanced in the cardiac tissues of tangeritin-treated group, relative to negative control group $(p<0.01)$. Histopathology revealed that tangeritin attenuated cadmium-induced cardiac injury in cadmium-exposed rats.

Conclusion: These results demonstrate the protective effect of tangeritin against cadmium-induced cardiotoxicity via attenuation of oxidative stress and pro-inflammatory mediators.
\end{abstract}

Keywords: Tangeritin, Cadmium, Cardiotoxicity, Oxidative stress, Anti-inflammation

\begin{abstract}
This is an Open Access article that uses a funding model which does not charge readers or their institutions for access and distributed under the terms of the Creative Commons Attribution License (http://creativecommons.org/licenses/by/4.0) and the Budapest Open Access Initiative (http://www.budapestopenaccessinitiative.org/read), which permit unrestricted use, distribution, and reproduction in any medium, provided the original work is properly credited.
\end{abstract}

Tropical Journal of Pharmaceutical Research is indexed by Science Citation Index (SciSearch), Scopus, International Pharmaceutical Abstract, Chemical Abstracts, Embase, Index Copernicus, EBSCO, African Index Medicus, JournalSeek, Journal Citation Reports/Science Edition, Directory of Open Access Journals (DOAJ), African Journal Online, Bioline International, Open-J-Gate and Pharmacy Abstracts

\section{INTRODUCTION}

Cadmium is a toxic heavy metal which has been implicated in carcinogenesis [1]. Cadmium toxicity occurs through environmental and occupational routes such fertilizers, batteries and sewage water [2]. Exposure to cadmium also occurs through dietary habits, contamination of drinking water and smoking [3]. Accumulation of cadmium in biological systems results in free radical generation thereby causing toxicity. Studies have revealed that cadmium poisoning 
occurs due to apoptosis, DNA damage and oxidative stress [4]. Cadmium poisoning results in cardiotoxicity and hypertension. Several evidence reveal that exposure to cadmium causes many cardiovascular diseases such as atherosclerosis, hypertension and myocardial infarction [5].

Natural products have shown therapeutic potential for the management of several disorders. Flavonoids have strong antioxidant activity and their medicinal uses have attracted the interest of researchers. Tangeritin is a flavonoid isolated from the peel of citrus fruits [6]. It possesses strong anti-inflammatory and antioxidant properties [7]. A report revealed that tangeritin suppresses the release of histamine from mast cells, and inhibits prostaglandin and cytokine release in LPS-stimulated microglia cells [8]. Moreover, it decreases the production of NO. Tangeritin possesses anti-Parkinsonism, anti-cancer and anti-microbial activities [9-11]. The present study was carried out to determine the effect of tangeritin on cadmium-induced cardiotoxicity in a rat model.

\section{EXPERIMENTAL}

\section{Animals}

Sprague Dawley rats (180 - $200 \mathrm{mg} / \mathrm{kg}$ ) were procured from Shanghai Medical College, China. The animals were housed in the laboratory with12-h light/12-h dark cycle at $25 \pm 2^{\circ} \mathrm{C}$ and 60 $\pm 5 \%$ humidity. The animal use protocols were approved by Institutional Animal Care and Use Committee (IACUC) of Capital Medical University, China (approval no. IACUC/CMU/02/2016-17). The animal handling followed the guidelines of Association for the Assessment and Accreditation of Laboratory Animal Care International (AAALAC) [12].

\section{Induction of cadmium toxicity}

The rats were divided into four groups: control group, negative control (which received cadmium chloride at $5 \mathrm{mg} / \mathrm{kg}$ ), and two tangeritin groups (10 and $20 \mathrm{mg} / \mathrm{kg}$ ). Cadmium toxicity was induced by intra-gastric administration of cadmium chloride at a dose of $5 \mathrm{mg} / \mathrm{kg}$ once daily for 4 weeks. The tangeritin groups received tangeritin at doses of 10 and $20 \mathrm{mg} / \mathrm{kg}$ p.o. 60 min prior to the administration of cadmium. The animals were anesthetized, and blood was collected from the retro-orbital plexus. Serum was separated out by centrifuging the blood for $10 \mathrm{~min}$ at $3000 \mathrm{~g}$. The rats were subsequently sacrificed by cervical dislocation and the heart was excised from each rat. The heart tissues were homogenized in $50 \mathrm{mM} 10 \%$ phosphate buffer solution. Biochemical parameters were estimated in blood, and also in the tissue homogenate.

\section{Determination of cadmium levels in serum and cardiac tissues}

Electro-thermal atomic absorption spectrometry was used for the estimation of concentration of cadmium in rat serum and heart using a Perkin Elmer Analyst 200 Gf. Calibration curve of standard cadmium was prepared by adding matrix modifier and tensoactive agent.

\section{Assessment of markers of cardiac function}

Activities of alkaline phosphatase (ALP), alanine transaminase $(A L T)$, lactate dehydrogenase $(\mathrm{LDH})$ and creatine kinase-MB (CK-MB) were determined using commercial kits (Biosystems SA, Spain) as per the instruction of the manufacturers. Chemiluminescence immunoassay was used for the estimation of serum cTnl and cTnT in the cadmium-exposed rats.

\section{Evaluation of antioxidant enzyme}

The activities of glutathione peroxidase (GPx), catalase (CAT), glutathione-S-transferase (GST) and superoxide dismutase (SOD) were determined in the tissue homogenate as per the instruction of the kit manufacturers ( $R$ \& $D$ system, USA).

\section{Determination of pro-inflammatory mediators}

Estimation of level of pro-inflammatory mediators i.e. IL-1, NO, NF-kB and TNF- $\alpha$ was done in the cardiac tissue homogenate using ELISA kits ( $R$ \& $D$ system, USA) as per the instruction given by the manufacturers.

\section{Western blot assay}

Cells from isolated brain were lysed in buffer containing protease inhibitor after washing it with PBS solution for the extraction of total protein. The lysate was centrifuged for $10 \mathrm{~min}$ at $12000 \times$ $g$ at $4{ }^{\circ} \mathrm{C}$. Bicinchoninic acid (BCA) assay kit was used for the estimation of concentration of total protein as per the instruction of the manufacturer. Gel electrophoresis was used for the fractionation of the total protein, and the separated proteins were transferred to PVDF membrane. The membrane was incubated overnight with the primary antibodies for caspase, Bax, Bcl2, $\mathrm{HO}-1, \mathrm{Nrf} 2$ and $\beta$-actin at 4 ${ }^{\circ} \mathrm{C}$ overnight. The membrane was further 
incubated with secondary antibodies, followed by chemiluminescence for the estimation of band intensity.

\section{Histopathological evaluation}

Isolated heart tissues were fixed in $4 \%$ paraformaldehyde and embedded in paraffin after dehydrating in alcohol. Microtome was used to section the heart tissue into $2-3 \mathrm{~mm}$ slices. The slices were thereafter stained with hematoxylin and eosin (H \& E) dye, and embedded in neutral de-paraffinized xylene medium. The slices were examined under a light microscope and the severity of lesions were graded as severe $(+++)$; moderate (++); mild (+), and nil (-).

\section{Statistical analysis}

Data are presented as mean \pm standard error of the mean (SEM, $n=6$ ). Graph Pad Prism 6.1 was used for data analysis ny one-way ANOVA followed by Dunnett's post hoc test. Values of $p$ $<0.05$ were considered significant.

\section{RESULTS}

\section{Effect of tangeritin on heart and serum cadmium levels}

The effect of tangeritin on the concentration of cadmium in the heart tissue and serum of cadmium-exposed rats is shown in Figure. 1. There was significant increase $(p<0.01)$ in the concentration of cadmium in the heart tissue and serum of the negative control group, when compared with the control group. However, treatment with tangeritin significantly decreased the serum and heart levels of cadmium in the cadmium-treated rats, relative to the negative control group $(p<0.01)$.

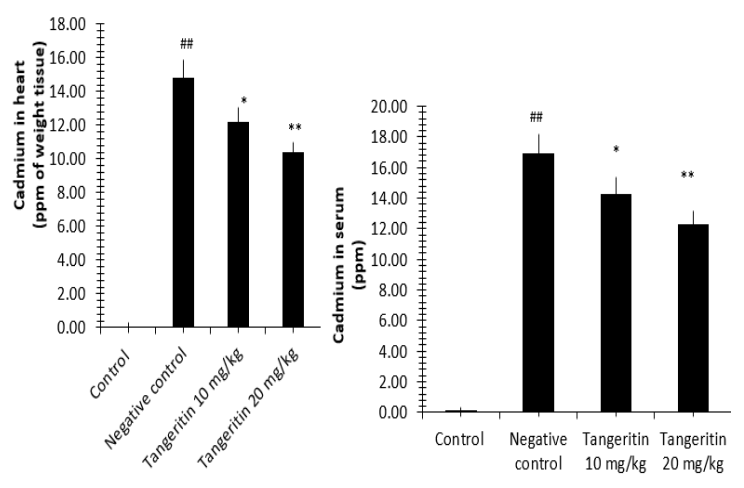

Figure 1: Tangeritin attenuated cadmium levels in the heart tissue and serum of cadmium-intoxicated rats. Results are presented as mean \pm SEM $(n=6) ;{ }^{\# \#} p<$ 0.01 , compared to control group; ${ }^{*} p<0.05,{ }^{* *} p<0.01$, compared to negative control
Effect of tangeritin on the markers of cardiac function
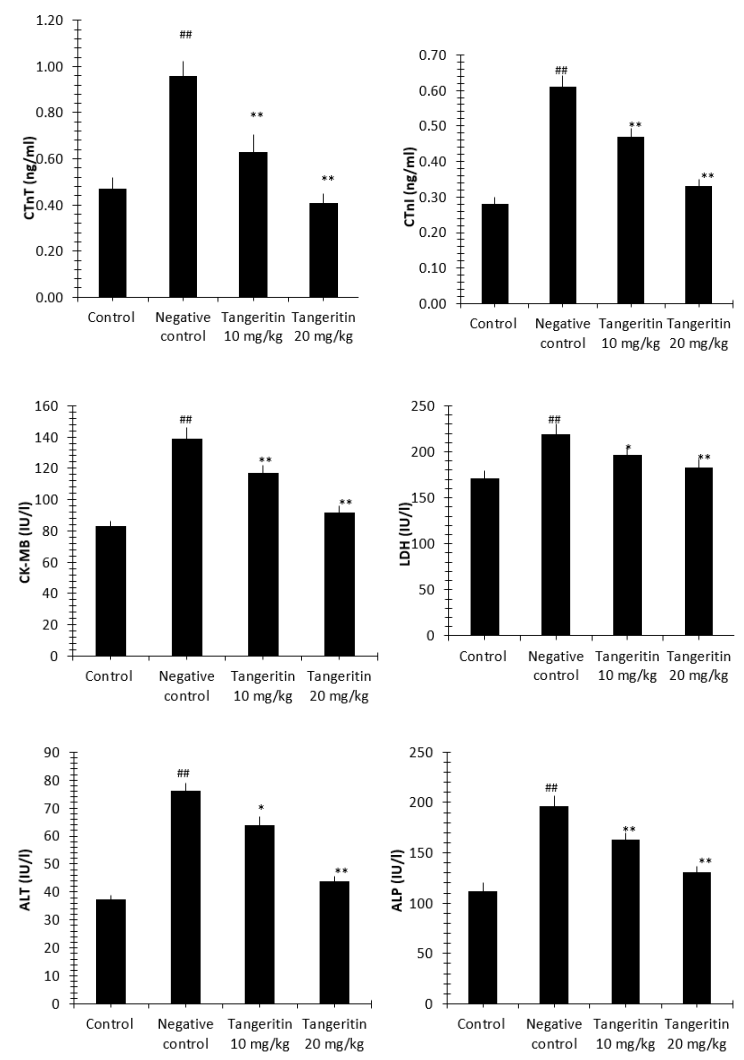

Figure 2: Tangeritin attenuated the markers of cardiac function (CTnT and CTnl) in the heart tissue, and serum CK-MB, LDH, ALT and ALP of cadmium-treated rats. Results are shown as mean $\pm \operatorname{SEM}(n=6) ;{ }^{\# \#} p<$ 0.01 , relative to control group; $p<0.05, p<0.01$, compared to negative control

The effect of tangeritin on the markers of cardiac function (CTnT and CTnl) in the heart tissue, and serum CK-MB, LDH, ALT and ALP of cadmiumexposed rats is shown in Figure 2. It was observed that the serum activities of CK-MB, LDH, ALT and ALP, and levels of CTnT and CTnl in the heart tissue were significantly increased $(p$ $<0.01)$ in the negative control group, when compared to the control group. However, treatment with tangeritin reduced the serum activities of CK-MB, LDH, ALT and ALP, as well as $\mathrm{tCTnT}$ and CTnl levels in the heart tissue of the cadmium-treated rats.

Effect of tangeritin on the activities of antioxidant enzymes

As shown in Figure 3, there were significant decreases in the activities of SOD, CAT, GST and GPx in the heart tissues of the negative control group, when compared to control group of rats $(p<0.01)$. However, the activities of SOD, CAT, GST and GPx in the heart tissues of tangeritin-treated group of rats were significantly 
increased, when compared to the negative control group $(p<0.01)$.
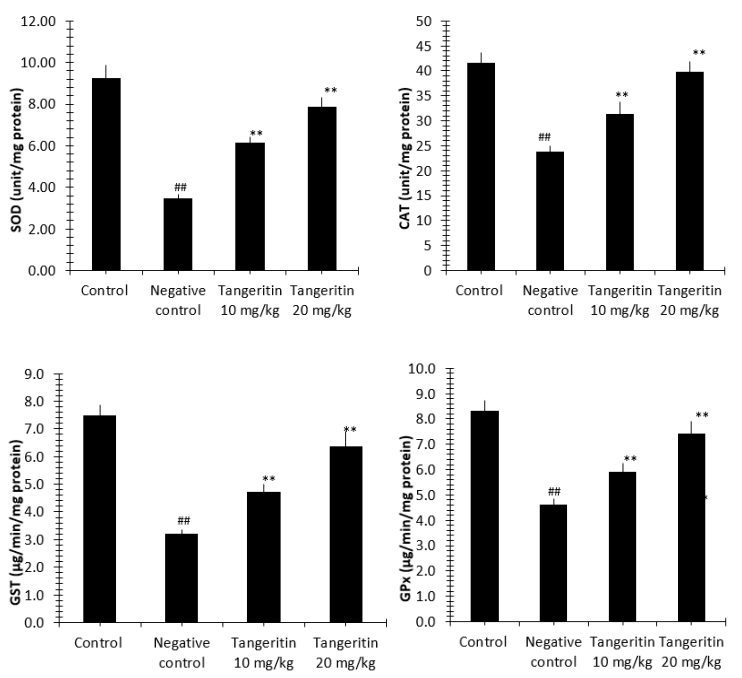

Figure 3: Tangeritin enhanced the activities of antioxidant enzymes SOD, CAT, GST and GPx in the heart tissues of cadmium-treated rats. Results are presented as mean $\pm \operatorname{SEM}(n=6) ;{ }^{\# \#} p<0.01$, compared with control group; $p<0.01$, compared with negative control

\section{Effect of tangeritin on pro-inflammatory mediators}

The effect of tangeritin on the levels of IL-1, NO, TNF- $\alpha$ and NF-kB in the heart tissue homogenate of cadmium-treated rats is shown in Table 1. There were significant upregulations in IL-1, NO, TNF-aand NF-kB in the heart tissue homogenate of the negative control group, when compared to control group of rats. However treatment with tangeritin significantly downregulated IL-1, NO, TNF- $\alpha$ and NF-kB in the heart tissue homogenate of the cadmiumexposed rats.

Effect of tangeritin on expressions of caspase-3, Bax, Bcl2, HO-1 and Nrf-2

As shown in Figure 4, Bcl-2, $\mathrm{HO}-1$ and $\mathrm{Nrf}-2$ were significantly downregulated, while Bax and caspase-3 were significantly upregulated in the heart tissue homogenate of the negative control group, relative to the control group. However, these altered expressions were significantly reversed by treatment with tangeritin.
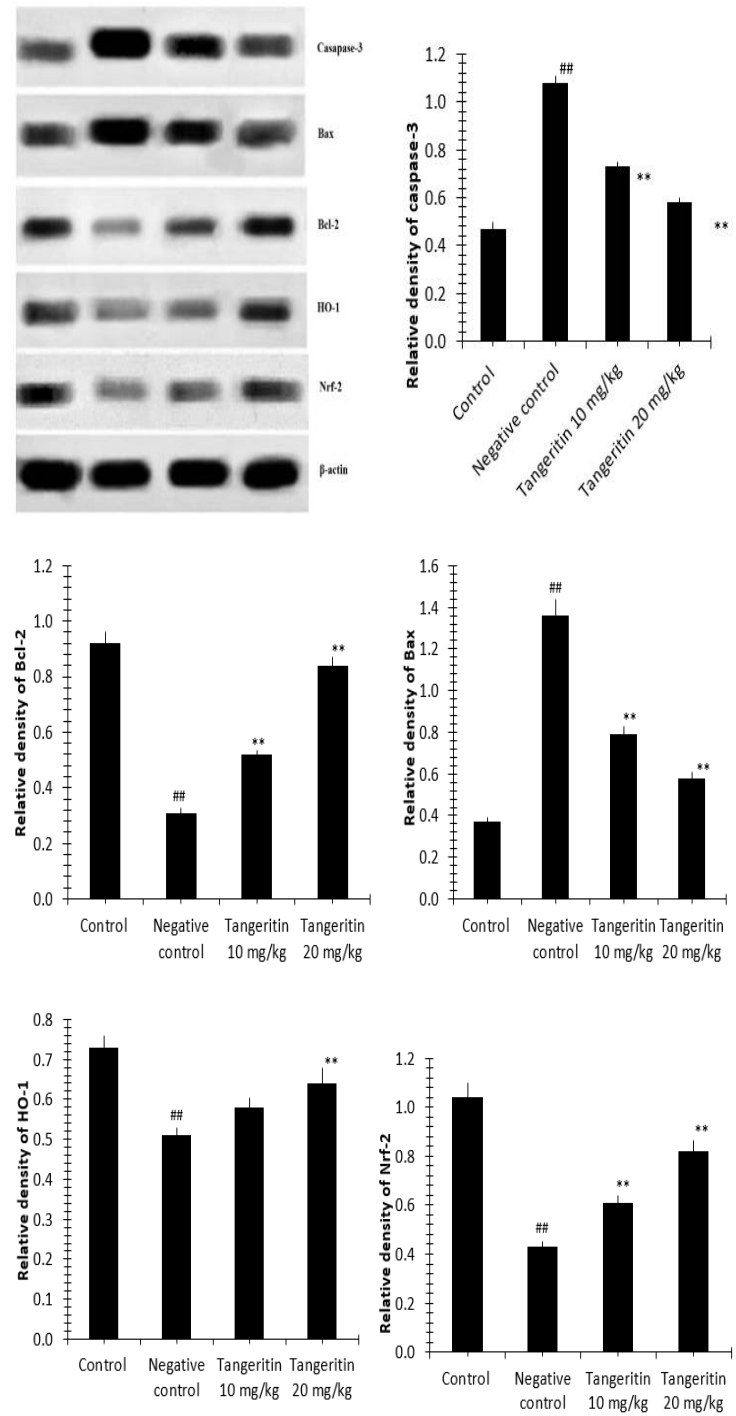

Figure 4: Effect of tangeritin on caspase-3, Bax, Bcl2, $\mathrm{HO}-1$ and Nrf-2 in the tissue homogenate of cadmiumexposed rats. Values are presented as mean \pm SEM $(\mathrm{n}=6) .{ }^{\#} p<0.01$, relative to control group; ${ }^{*} p<0.05$, $p<0.01$, relative to negative control group

Table 1: Tangeritin downregulated IL-1, NO, TNF- $\alpha$ and NF-kB in the heart tissue homogenate of cadmiumexposed rats

\begin{tabular}{|c|c|c|c|c|}
\hline Group & $\begin{array}{c}\text { IL-1 }(\mathrm{pg} / \mathrm{mg} \text { of } \\
\text { tissue) }\end{array}$ & $\begin{array}{c}\mathrm{NO}(\mathrm{nmol} / 100 \mathrm{mg} \\
\text { tissue) }\end{array}$ & $\begin{array}{c}\text { TNF- } \alpha \text { (pg/mg of } \\
\text { tissue) }\end{array}$ & $\begin{array}{c}\text { NF-kB (ng/mg of } \\
\text { protein) }\end{array}$ \\
\hline Control & $17.49 \pm 1.13$ & $20.91 \pm 1.83$ & $13.92 \pm 1.14$ & $20.58 \pm 2.06$ \\
\hline Negative control & $36.84 \pm 2.72^{\# \#}$ & $38.26 \pm 3.13^{\# \#}$ & $26.74 \pm 2.32^{\# \#}$ & $46.82 \pm 3.75^{\# \#}$ \\
\hline Tangeritin $10 \mathrm{mg} / \mathrm{kg}$ & $24.71 \pm 1.83^{\star *}$ & $31.97 \pm 2.72^{*}$ & $20.97 \pm 2.07^{\star *}$ & $37.64 \pm 2.24^{\star \star}$ \\
\hline Tangeritin $20 \mathrm{mg} / \mathrm{kg}$ & $20.86 \pm 1.47^{\star *}$ & $26.56 \pm 2.33^{\star *}$ & $15.73 \pm 1.39 * *$ & $26.87 \pm 2.17^{\star *}$ \\
\hline
\end{tabular}
negative control 
Table 2: Mitigation of histopathological score in the cardiac tissues of cadmium-treated rats by tangeritin

\begin{tabular}{lcccc}
\hline Group & $\begin{array}{c}\text { Cardiac } \\
\text { inflammation }\end{array}$ & $\begin{array}{c}\text { Cardiac } \\
\text { necrosis }\end{array}$ & $\begin{array}{c}\text { Wide myofibrillar } \\
\text { space }\end{array}$ & $\begin{array}{c}\text { Cardiac myofibril } \\
\text { degeneration }\end{array}$ \\
\hline Control & - & - & - & - \\
Negative control & +++ & ++ & +++ & +++ \\
Tangeritin $10 \mathrm{mg} / \mathrm{kg}$ & + & + & ++ & ++ \\
Tangeritin $20 \mathrm{mg} / \mathrm{kg}$ & + & + & + & + \\
\hline
\end{tabular}

Data are mean \pm SEM $(\mathrm{n}=6) ;+++=$ severe $;++=$ moderate; + = mild; - = none

\section{Effect of tangeritin on histopathological changes}

The effects of tangeritin on histopathological changes and histopathological lesion grades in the cardiac tissues of cadmium-toxified rats are shown in Figure 5 and Table 2, respectively. Heart tissues of control group of rats showed normal cardiac fibers. However, histopathological lesions such as cardiac necrosis, inflammation, wide myofibrillar space and cardiac myofibril degeneration were observed in the heart tissues of the cadmium-treated rats. Tangeritin treatment mitigated the cadmium-induced disruption of cardiac myofibrils in the heart tissues.

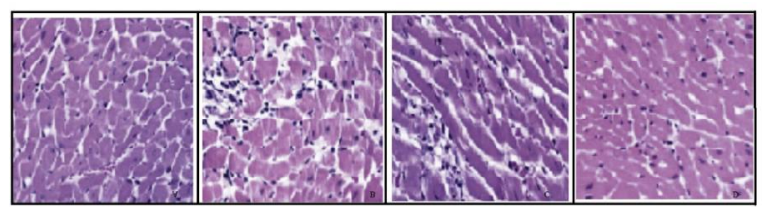

Figure 5: Mitigation of cadmium-induced cardiac tissue histopathological lesions in rats by tangeritin. A: control; B: Negative control; C: Tangeritin (10 mg/kg); D: Tangeritin $(20 \mathrm{mg} / \mathrm{kg})$

\section{DISCUSSION}

Oxidative stress is one of the major factors that contribute to the development of cardiovascular diseases by enhancing the production of ROS. Cadmium provokes toxicity in myocardial tissues by enhancing the generation of ROS [13]. Natural products have shown potential beneficial effects in the management of cadmium-induced myocardial toxicity. Thus, the present study was aimed at determining the protective effect of tangeritin on cadmium-induced myocardial toxicity. The rats were exposed to cadmium for 4 weeks, along with tangeritin administration. The levels of cadmium in serum and cardiac tissue were determined, as well as markers of cardiac function, activities of antioxidant enzymes, and levels of pro-inflammatory mediators. Furthermore, western blot assay and histopathology studies were done to determine the molecular mechanisms of action of tangeritin.

Studies have revealed that accumulation of cadmium in cardiac tissues results in toxicity [14].
In the present study, the concentrations of cadmium in serum and cardiac tissue were significantly reduced when compared to the negative control group. This is consistent with earlier findings [15]. It has also been reported that CTnT and CTnl in the heart tissue, and serum levels of CK-MB, LDH, ALT and ALP are increased in myocardial diseases [16]. Drugs that have shown beneficial effects in cardiovascular diseases attenuate increases in the levels of cardiac function markers. This is in agreement with the tangeritin-induced significant decreases in these markers of cardiac function, relative to the negative control group.

Cadmium exposure enhances the generation free radicals and production of ROS [17]. Oxidative stress and pro-inflammatory mediators enhance cadmium-induced myocardial toxicity which induces apoptosis in cardiac tissue cells [18]. The results of the present study indicate that the cadmium-induced alterations in activities of antioxidant enzymes, and changes in levels of pro-inflammatory mediators in cardiac tissues were reversed by tangeritin treatment.

Apoptosis is regulated by Bax protein which promotes the permeability of mitochondrial membrane, while cadmium enhances mitochondrial membrane damage due to induction of oxidative stress [19]. The data from this study reveal that tangeritin downregulated caspase-3, Bax and $\mathrm{Bcl}-2$ proteins, thereby reducing cadmium-induced apoptosis in cardiac cells. Previous studies suggest that enhancement in the activities of antioxidant enzymes reduces the expression of Nrf-2 protein due to enhanced production of ROS, while cadmium exposure reduces Nrf-2 [20]. In this study, treatment with tangeritin attenuated the altered expressions of Nrf-2, thereby mitigating the cadmium-induced cardiotoxicity. Histopathology studies also showed that tangeritin attenuated the cadmium-induced cardiac injury.

\section{CONCLUSION}

The findings from this study show that tangeritin exerts protective effect against cadmium-induced cardiotoxicity through attenuation of oxidative 
stress and downregulation of pro-inflammatory mediators in rats. It also reduces apoptosis in cardiac cells via Nrf-2 pathway. These results suggest that tangeritin might be clinically useful as a cardio-protective agent in the management of myocardial infraction and hypertension.

\section{DECLARATIONS}

\section{Acknowledgement}

The authors are thankful to Heart Center \& Beijing Key Laboratory of Hypertension Disease, China and National Research Institute for Health and Family Planning, China for providing the required facilities for this work.

\section{Conflict of Interest}

No conflict of interest associated with this work.

\section{Contribution of Authors}

The authors declare that this work was done by the authors named in this article and all liabilities pertaining to claims relating to the content of this article will be borne by them.

\section{REFERENCES}

1. Kim HS, Kim YJ, Seo YR. An Overview of Carcinogenic Heavy Metal: Molecular Toxicity Mechanism and Prevention. J Cancer Prev 2015; 20(4): 232-240.

2. Rafati Rahimzadeh M, Rafati Rahimzadeh M, Kazemi S, Moghadamnia A. Cadmium toxicity and treatment: An update. Caspian J Intern Med. 2017; 8(3): 135-145.

3. Jaishankar M, Tseten T, Anbalagan N, Mathew BB, Beeregowda KN. Toxicity, mechanism and health effects of some heavy metals. Interdiscip Toxicol. 2014; 7(2): 60-72.

4. Skipper A, Sims JN, Yedjou CG, Tchounwou PB. Cadmium Chloride Induces DNA Damage and Apoptosis of Human Liver Carcinoma Cells via Oxidative Stress. Toscano $W$, ed. Int J Environ Res Public Health 2016; 13(1): 88.

5. Solenkova NV, Newman JD, Berger JS, Thurston G, Hochman JS, Lamas GA. Metal Pollutants and Cardiovascular Disease: Mechanisms and Consequences of Exposure. Am Heart J 2014; 168(6): 812-822.

6. Wang L, Wang J, Fang L, et al. Anticancer Activities of Citrus Peel Polymethoxyflavones Related to Angiogenesis and Others. Biomed Res Int 2014; 2014. 453972.

7. Lee YY, Lee EJ, Park JS, Jang SE, Kim DH, Kim HS. Anti-Inflammatory and Antioxidant Mechanism of
Tangeretin in Activated Microglia. I Neuroimmune Pharmacol 2016; 11(2): 294-305.

8. Dong H, Zhang X, Wang Y, Zhou X, Qian Y, Zhang S., Suppression of Brain Mast Cells Degranulation Inhibits Microglial Activation and Central Nervous System Inflammation. Mol Neurobiol 2017; 54(2): 997-1007.

9. Braidy N, Behzad S, Habtemariam S, Ahmed T, Daglia M, Nabavi SM, Sobarzo-Sanchez E, Nabavi SF. Neuroprotective Effects of Citrus Fruit-Derived Flavonoids, Nobiletin and Tangeretin in Alzheimer's and Parkinson's Disease. CNS Neurol Disord Drug Target. 2017; 16(4): 387-397.

10. Dong Y, Cao A, Shi J, Yin P, Wang L, Ji G, Xie J, Wu D, Tangeretin, a citrus polymethoxyflavonoid, induces apoptosis of human gastric cancer AGS cells through extrinsic and intrinsic signaling pathways. Oncol Rep. 2014; 31(4): 1788-1794.

11. Xiaolin Yao, Xinrong Zhu, Siyi Pan, Yapeng Fang, Fatang Jiang, Glyn O Phillips, Xiaoyun Xu. Antimicrobial activity of nobiletin and tangeretin against Pseudomonas. Food Chem 2012; 132 (4): 1883-1890.

12. Bhattacharyya A, Chattopadhyay R, Mitra S, Crowe SE. Oxidative Stress: An Essential Factor in the Pathogenesis of Gastrointestinal Mucosal Diseases. Physiolog Rev 2014; 94(2): 329-354.

13. Guide for the Care and Use of Laboratory Animals: Eighth Edition Committee for the Update of the Guide for the Care and Use of Laboratory Animals; National Research Council. 2010; ISBN: 0-309-15401-4.

14. Li Q, Liu H, Alattar M, Jiang S, Han J, Ma Y, Jiang C. The preferential accumulation of heavy metals in different tissues following frequent respiratory exposure to PM2.5 in rats. Scient Rep. 2015; 5: 16936.

15. Priya LB, Baskaran R, Elangovan $P$, Dhivya V, Huang CY, Padma VV. Tinospora cordifolia extract attenuates cadmium-induced biochemical and histological alterations in the heart of male Wistar rats. Biomed Pharmacother 2017; 87: 280-287.

16. Al-Hadi HA, Fox KA. Cardiac Markers in the Early Diagnosis and Management of Patients with Acute Coronary Syndrome. Sultan Qaboos Univ Med J. 2009; 9(3): 231-246.

17. Liu J, Qu W, Kadiiska MB. Role of oxidative stress in cadmium toxicity and carcinogenesis. Toxicol Appl Pharmacol 2009; 238(3): 209-214.

18. Nazimabashir, Manoharan V, Miltonprabu S. Cadmium induced cardiac oxidative stress in rats and its attenuation by GSP through the activation of Nrf2 signaling pathway. Chem Biol Interact. 2015; 5; 242: 179-193.

19. Webster KA. Mitochondrial membrane permeabilization and cell death during myocardial infarction: roles of calcium and reactive oxygen species. Future cardiol 2012; 8(6): 863 - 884.

20. Ma Q. Role of Nrf2 in Oxidative Stress and Toxicity. Annu Rev Pharmacol Toxicol 2013; 53: 401-426. 